\title{
A patient with fever, chest pain and a rapidly changing chest X-ray
}

\author{
Bas de Groot • Daan Brand • Tessel N. E. Vossenberg • \\ Andrea Warnemunde
}

Received: 9 September 2010 / Accepted: 13 September 2010/Published online: 26 October 2010

(C) The Author(s) 2010. This article is published with open access at Springerlink.com

\begin{abstract}
A 58-year-old male presented to the emergency department with fever, malaise and right-sided chest pain, aggravating during inspiration. Two days prior to presentation, he had been discharged home from another hospital with antibiotics for a suspected urinary tract infection. Chest X-ray and $\mathrm{CT}$ scan, trans-thoracic echocardiography and blood cultures had not revealed any abnormalities during that hospital admission. The patient had a Bentall procedure with aortic valve replacement, complicated by cardiac tamponade 2 years earlier. Since then his body weight had gradually decreased by $20 \mathrm{~kg}$, and there had been intermittent low-grade fever.
\end{abstract}

The diagnosis was prosthetic valve endocarditis (PVE) with partial dehiscence of the prosthesis resulting in a contained mediastinal hematoma. The chest radiograph showed a circular paracardial structure (Fig. 1) that was not present on the chest X-ray 2 days prior to presentation. The dramatic change in the plain chest film over 2 days is suggestive of a rapidly developing false aneurysm or haemorrhage. CT scan of the chest revealed extravasation of contrast cranial to the aortic valve (Fig. 2: white arrow) with a contained hematoma in the anterior and middle mediastinum. PVE occurs with a 3-6\% accumulative

B. de Groot $(\bowtie) \cdot$ D. Brand $\cdot$ A. Warnemunde

Department of Emergency Medicine,

Leiden University Medical Center,

Albinusdreef 2, Postbus 9600, 2300 RC Leiden, The Netherlands

e-mail: b.de_groot.CEH@lumc.nl

T. N. E. Vossenberg

Department of Cardiology, Leiden University Medical Center, Leiden, The Netherlands frequency 5 years after surgery, with the highest incidence in the first year [1]. The $\sim 11$ year probability of bleeding is 19 to $42 \%$, occurring more frequently in mechanical valves because of the lifelong anti-coagulation [2,3]. PVE can be treated with antibiotics alone unless there is evidence of bleeding [4], as was the case for our patient, who was admitted to the intensive care unit after replacement of the prosthesis, where he gradually recovered.

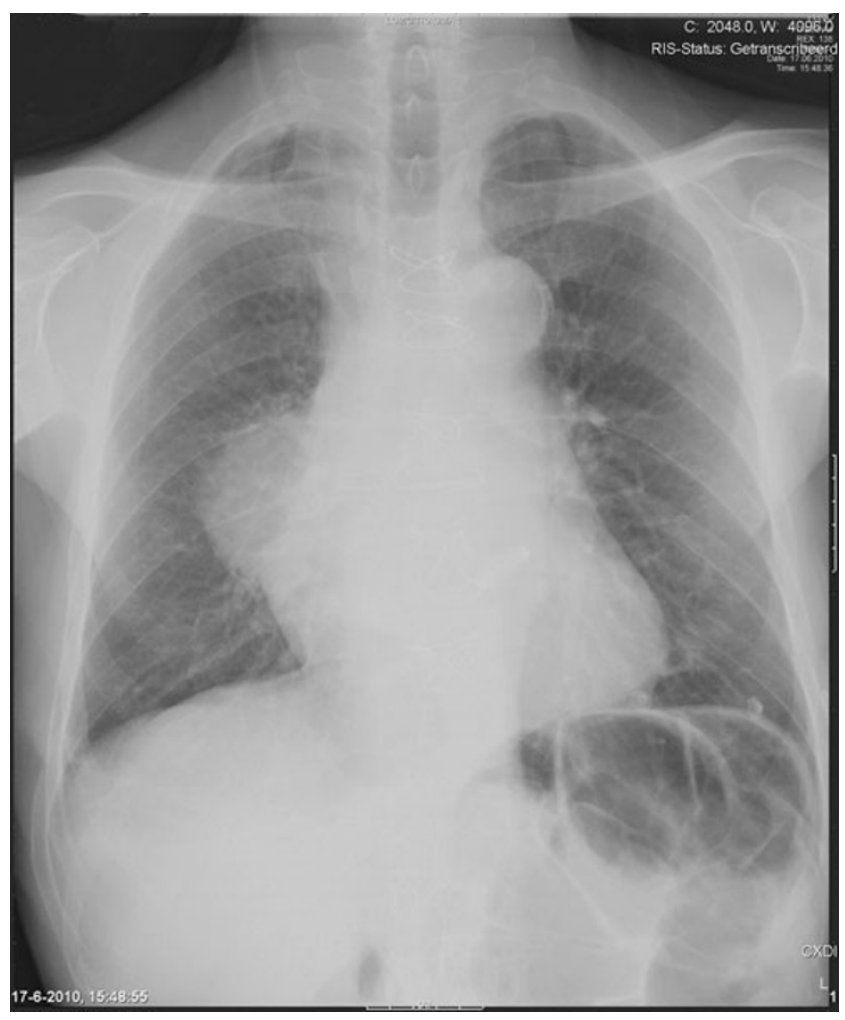

Fig. 1 Chest X-ray made during current presentation 


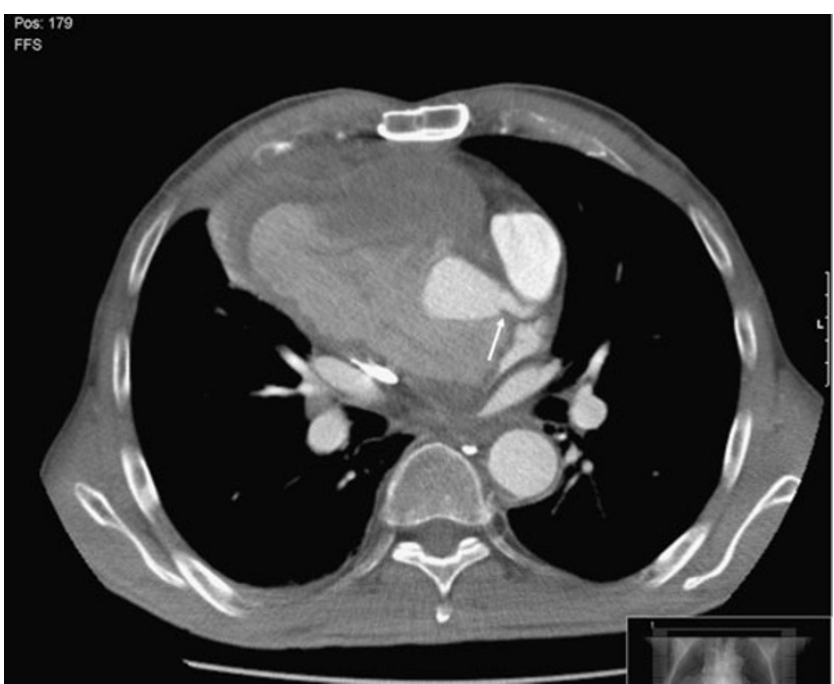

Fig. 2 Contrast-enhanced CT scan of the chest

Open Access This article is distributed under the terms of the Creative Commons Attribution Noncommercial License which per- mits any noncommercial use, distribution, and reproduction in any medium, provided the original author(s) and source are credited.

\section{References}

1. Karchmer AW (1999) In: Mandell GL et al (eds) Principles and practice of infectious diseases, 5th edn. Churchill Livingstone, Philidelphia, p 903

2. Hammermeister KE, Sethi GK, Henderson WG et al (1993) The Veterans Affairs Cooperative Study on Valvular Heart Disease: A comparison of outcomes in men 11 years after heart valve replacement with a mechanical valve or bioprosthesis. N Engl $\mathrm{J}$ Med 328:1289

3. Bloomfield P, Wheatley DJ, Prescott RJ, Miller HC et al (1991) Twelve year comparison of a Bjork-Shiley mechanical heart valve with porcine bioprosthesis. N Engl J Med 324:573

4. Bonow RO, Carabello BA, Chatterjee K et al (2006) ACC/AHA 2006 guidelines for the management of patients with valvular heart disease. A report of the American College of Cardiology/ American Heart Association Task Force on Practice Guidelines (Writing committee to revise the 1998 guidelines for the management of patients with valvular heart disease). J Am Coll Cardiol 48:e1 